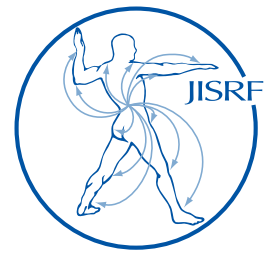

\title{
Osteoarthritis or Osteoarthrosis: Commentary on Misuse of Terms
}

Tanchev $P^{1}$

$\mathrm{M}$ edical terminology is an important tool for communication among medical practitioners, researchers, and scientists. The precise use of terms ensures a successful orientation in the field of medical practice contributing to the adequate treatment of patients.

The subject of this commentary is the misuse of the terms "osteoarthritis" and "osteoarthrosis" in the specialty of orthopedic surgery. Contemporary literature, journals, media, etc., especially those in English language, are dominated by the use of the term "osteoarthritis" for the most common pathological condition, namely the degenerative joint disease. Leading speakers at prestigious international scientific meetings persistently use the term "osteoarthritis". "Osteoarthritis" is derived from the Greek word part osteo-, meaning "bone", combined with arthritis: arthr-, meaning "joint", and -itis. Strictly taken, this application is incorrect. Because the suffix "-itis" implies the presence of inflammation. Therefore, "osteoarthritis" should be considered misleading since inflammation is not a primary feature of the degenerative joint disease. Here the mechanical stress, avascular necrosis, posttraumatic sequelae, metabolic causes, etc. are the etiopathophysiological factors leading to the process of joint cartilage "tear and wear" (degeneration, noninflammatory breakdown). The term "osteoarthrosis" is correct for degenerative joint disease. Inflammation may play only a secondary or concomitant role in this condition. This is in contrast to rheumatoid arthritis, which is primarily an inflammatory pathologic entity. In short, "osteoarthritis" means inflammation of the joint, while "osteoarthrosis" means degeneration of the joint.

Unfortunately, this terminological misuse and embarrassment in the Anglo-Saxon literature and practice is nourished by some famous medical dictionaries with multiple editions (Dorland's Illustrated Medical Dictionary, Stedman's Medical Dictionary, Stedman's Medical Terminology, etc). $[\underline{1}, \underline{2}, \underline{3}]$ In general, the reader may find the following terms and explanations:

- osteoarthritis - "noninflammatory degenerative joint disease... characterized by degeneration of the articular cartilage, hypertrophy of the bone at the margins, and changes in the synovial membrane..."

- osteoarthrosis - "chronic arthritis of noninflammatory character"

- osteoarthritis - "inflammation of bone and joint", but also "osteoarthrosis is another name for the chronic condition known as osteoarthritis"

\footnotetext{
1 Panayot Tanchev, MD

Professor Emeritus of Orthopedic and Trauma Surgery

Former Chief Surgeon, Department of Spine Surgery

Gorna Bania University Hospital of Orthopedics and Traumatology

Medical University of Sofia, Bulgaria, Buzludzha Str. 40 App. 8, 1463

Sofia, BULGARIA

ptanchev@abv.bg

(Direct reprint requests to Panayot Tanchev)
}

(C) 2017 Tanchev. All rights reserved.

Authors retain copyright and grant the journal right of first publication with the work. Reconstructive Review is an open access publication and

follows the Creative Commons Attribution-NonCommercial CC OPEN 6 ACcess BY-NC. This license allows anyone to download works, build

upon the material, and share them with others for non-commercial purposes as long as they credit the senior author, Reconstructive Review, and the Joint Implant Surgery \& Research Foundation (JISRF). An example credit would be: "Courtesy of (senior author's name), Reconstructive Review, JISRF, Chagrin Falls, Ohio". 
- osteoarthrosis - "chronic, noninflammatory arthritis"

What is it? These definitions are plainly self-contradictory per se. In fact, the attentive reader would just find himself in a terminological trap.

I feel the term "osteoarthritis" is just so ingrained in USA, Great Britain and the other English-speaking countries that there is virtually no chance that it would change. If one would switch to "osteoarthrosis" there, it would likely cause confusion. During some international scientific meetings (where English was the official language) I asked English-speaking colleagues why do they still use incorrectly the term "osteoarthritis" for degenerative joint disease. The answers ranged from habit, cast of mind, tradition, disposition, inertia, etc. to a confusing unwillingness for change. Some colleagues said that trying to change such a popular misuse of medical terminology would be "a lost battle".

Recently, striving to collect some current opinions and provoke a discussion I asked a question on ResearchGate (a social networking site for medical practioners, researcheres and scientists): Why English-speaking colleagues still use incorrectly the term "osteoarthritis" for degenerative joint disease? [4] I received more than 30 thoughtful posts by serious researchers and medical practitioners. And the general opinion was that there was enough evidence for correctional change of this obvious misuse.

I have to underline, that, in contrast, this awkward situation with the terms "osteoarthritis" and "osteoarthrosis" may be juxtaposed on and compared with the never-happening misuse of "spondylitis" instead of "spondylosis", "discitis" instead of "discosis", "periostitis" instead of "periostosis", "osteochondritis" instead of "osteochondrosis" and many other pathological entities where the semantic differentiation corresponds to the etiology, pathophysiology, diagnostics, therapy, etc. With these examples the misuse of terms is unwarranted and unbelievable. They are clearly and correctly defined in the medical literature and practice.

Consequently, the treatment modalities differ significantly.

On the other hand, it should be marked that Russian, German, French and most European orthopedic surgeons refer to the degenerative joint disease as "osteoarthrosis" to signify the lack of inflammatory response. This is historically substantiated ever since the time when the name "Orthopédie" was introduced by the French physician Nicholas Andry in his famous book "L'Orthopédie ou l'art de prevenir et corriger les difformitées du corps chez les enfants" in 1741, in which mechanical overloading was considered to be the main etiological factor for poor body posture, spinal deformity, and joint disorders.
In the 19th century and the first half of the 20th century the practice and theory of European orthopedics were strongly influenced by the French and German textbooks where the denomination "arthrosis deformans" (from Greek/Latin) was predominantly used. This term is still in use in most European countries. However, in the second half of the 20th century, when world medicine came under the strong influence of the Anglo-Saxon literature and science, "osteoarthritis" became the preferred word used for degenerative joint disease..

In fact, osteoarthrosis (in English literature "osteoarthritis") is a degenerative joint disease but may have different origin. The most important point here is what is the primum movens for this variety of pathological conditions. Although primary (idiopathic) osteoarthrosis occurs, the majority of osteoarthrosis types are of secondary nature, e.g. following DDH, intraarticular fractures or cartilage injuries, static disorders, sports overloading, state after femoral head osteonecrosis, metabolic and endocrine disorders, etc. All these are non-inflammatory conditions. The most important pathophysiological factor for degeneration of the joint is the mechanical stress leading to progressive cartilage wear and damage.

Precise terminology is very important, especially in medical practice, where it is directly related to diagnostics and treatment, and consequently to clinical results and outcomes. In fact, some English-speaking surgeons demonstrate some readiness for change. However, the majority remain stubborn explaining the wrong use of term as a bad habit, tradition, disposition, inertia... Bad habits should be subjected to correction. Although the Anglo-Saxon literature is very influential, it is time for repentance, namely a correct use of terms.

Meanwhile, the English-speaking authors started using "OA" for noninflammatory joint diseases. The acronym OA seems to be a "salvage" solution of the existing terminological disturbance. But who can tell what hides behind OA? Probably, it makes things more comfortable and less negligent, but it does not correct the terminological cast of mind. I believe it will only change if we all keep repeating what is correct and what is incorrect. A thought-provoking discussion would be also very useful.

\section{References:}

1. Stedman's Medical Dictionary. Williams \& Wilkins, Baltimore, Philadelphia, Hong Kong, London, Munich, Sydney, Tokyo, 28th Edition, 2005

2. Dorland's Illustrated Medical Dictionary. W.B.Saunders Co., Philadelphia, London, Toronto, Montreal, Sydney, Tokyo, 32nd Edition, 2015

3. Stedman's Medical Terminology: Steps to Success in Medical Language. William\& Wilkins, 2010 https://books.google.bg/books/about/Stedman s Medical_ Terminology.html?id=YISsnVIEJgkC\&redir esc=y

4. www.researchgate.net/post/Why English-speaking colleagues still use incorrectly the term osteoarthritis for degenerative joint disease 